\title{
Beyond English only: Addressing language interpretation in professional psychology training
}

Timothy B. Smith

Brigham Young University, tbs@byu.edu

Clay A. Frandsen

Brigham Young University

Derek Griner

Brigham Young University

Domenech Rodriguez

Guillermo Bernal

University of Puerto Rico, Rio Piedras

Follow this and additional works at: https://scholarsarchive.byu.edu/facpub

Part of the Other Psychiatry and Psychology Commons

\section{BYU ScholarsArchive Citation}

Smith, Timothy B.; Frandsen, Clay A.; Griner, Derek; Rodriguez, Domenech; and Bernal, Guillermo, "Beyond English only: Addressing language interpretation in professional psychology training" (2019). Faculty Publications. 3141.

https://scholarsarchive.byu.edu/facpub/3141

This Peer-Reviewed Article is brought to you for free and open access by BYU ScholarsArchive. It has been accepted for inclusion in Faculty Publications by an authorized administrator of BYU ScholarsArchive. For more information, please contact ellen_amatangelo@byu.edu. 
Frandsen, C., Smith, T. B., Griner, D., \& Beecher, M. (2019). Beyond English only: Addressing language interpretation in professional psychology training. Training and Education in Professional Psychology, 13(1), 64-71.http://dx.doi.org/10.1037/tep0000212

Beyond English Only: Addressing Language Interpretation

in Professional Psychology Training 


\begin{abstract}
Professional guidelines direct that psychologists working with clients with limited English proficiency should involve an interpreter if a mental health professional fluent in the client's language is unavailable. However, complexities of interpreted therapy require training. We describe nine relevant areas of trainee skill acquisition and also surveyed 102 multicultural course instructors in APA-accredited psychology programs regarding current professional training. Only 55 (54\%) instructors reported providing any training on working with language interpreters, with $16(16 \%)$ providing more than 2 hours of training. Instructors ranked nine proposed skill areas and gave recommendations for overcoming barriers and working with interpreters to assist clients with limited English proficiency. The proposed areas of professional competence provide starting points for therapists learning the complexities of interpreted therapy.
\end{abstract}

Keywords: psychotherapy, language interpretation, language translation, cross-cultural, competence 
Beyond English Only: Addressing Language Interpretation

in Professional Psychology Training

Approximately $22 \%$ of the U.S. population, over 66 million individuals, communicate at home in a language other than English, and 26 million have limited English proficiency (LEP; U.S. Census Bureau, 2016). Individuals strongly prefer to receive mental health services in their primary language (Villalobos et al., 2016), process emotional content better in their primary language (e.g., Espín, 2013), and experience better outcomes from therapy conducted in their preferred language (Soto, Smith, Griner, Domenech Rodríguez, \& Bernal, 2018).

However, most U.S. psychologists communicate exclusively in English (APA, 2018) and have received extremely limited training on how to work with clients who communicate in other languages, including American Sign Language (ASL; Eckert \& Rowley, 2013; Glickman, 2013). Implicit assumptions regarding universal spoken English perpetuate both racial privilege and audism, audiocentric perspectives that receive insufficient attention (Eckert \& Rowley, 2013). Inadequate therapist preparation to meet clients' language needs clearly impacts mental health treatments (Espín, 2013), which require intensive communication between therapist and client.

\section{Need for Training to Work with Language Interpreters}

LEP strongly predicts mental health treatment avoidance and premature termination (e.g., Derr, 2015; Ohtani, Suzuki, Takeuchi, \& Uchida, 2015). The following vignette highlights some concerns of a potential client. Aseel (pseudonym), a Syrian widow at age 32 who speaks limited English, arrived at her cousin's house in a U.S. city just prior to the 2016 elections. Through her cousin and Arabic news sites she learned of increasing ethnic insults in the U.S. Aseel dared not venture outside, but after a year of isolation her symptoms of PTSD from the Syrian civil war worsened to the point where she obviously needed treatment. But how would that be possible? 
Thousands of people with LEP like Aseel do not receive needed mental health services (e.g., Durbin, Sirotich, \& Durbin, 2017). Refugees, immigrants, and people of color underutilize and prematurely discontinue mental health services (Prendes-Lintel, 2001; Smith \& Trimble, 2016).

These concerns have been known for decades. Title VI of the 1964 Civil Rights Act directs public service providers to offer interpretation and translation services to individuals with LEP. Since 1978 the U.S. judicial system has mandated language interpretation when necessary for legal proceedings (Mikkelson, 2016). Over time, language training for physicians and language accommodations for patients in medical hospitals have become increasingly prevalent (e.g., Chiam et al., 2017; Hsieh, 2016; Jacobs \& Diamond, 2017), but relevant mental health training and services have lagged behind (e.g., Becher \& Wieling, 2015). The 1993 guidelines from the American Psychological Association (APA) instructed psychologists to provide services in the language requested by the client, with interpreter facilitation as needed. APA's (2003) Guidelines for Multicultural Education, Training, Research, Practice and Organizational Change for Psychologists included "respecting the language preference of the client" (p. 50). Unfortunately, a recent review (Fouad, Santana, \& Ghosh, 2017) concluded that these guidelines have had limited impact, with hardly any attention given to specific guidelines such as language accommodations. Language interventions for clients with LEP remain deficient (Ohtani et al., 2015), even in multilingual urban areas, with therapists primarily relying on ad hoc interpretation by clients' family or friends in non-emergency/routine practice (Brisset et al., 2014), despite the many problems and ethical dilemmas posed by that arrangement (Flores, 2005).

A plausible solution to enact professional guidelines is to provide effective multicultural education to the rising generation of psychologists (e.g., Smith, Constantine, Dunn, Dinehart, \& Montoya, 2006). All theoretical models of therapist multicultural competence emphasize 
effective communication (e.g., Sue, Arredondo, \& McDavis, 1992), and multiculturally competent therapy with clients with LEP involves multilingual therapists when possible and language interpretation when necessary (Brach \& Fraserirector, 2000). Language interpretation becomes necessary when psychologists cannot communicate fluently in ASL or Arabic, let alone Nepali, Somali, and other languages spoken by many immigrants and refugees in North America (APA, 2018; Prendes-Lintel, 2001). Psychologists should be prepared to work with professional language interpreters until a therapist fluent in the client language is located.

Involving an interpreter in psychotherapy increases the complexity of clinical work (Brisset et al., 2013; Hunt \& Swartz, 2017; Jacobs \& Diamond, 2017), such that clinicians and graduate trainees need to receive explicit instruction to practice within bounds of competence (Hatcher et al., 2013) when working with clients who have LEP or are Deaf (Glickman, 2013). Considerations that require training include confidentiality, relationship dynamics, interpretation accuracy, inappropriate intervention or transference of personal beliefs by interpreters, dual roles between client and interpreter, and interpreters' inadequate familiarity with mental health issues (Paone \& Malott, 2008). Effective work with language interpreters requires training (PrendesLintel, 2001; Searight \& Searight, 2009; Tribe \& Thompson, 2011; Yakushko, 2010). However, graduate programs in mental health may offer minimal instruction to prepare trainees to make language accommodations (Searight \& Armock, 2013; Tribe \& Raval, 2003).

\section{Relevant Instruction and Guidelines}

We located no prior research on current training practices for language interpretation in APA-accredited programs. If psychologists work with interpreters, they often do so without the benefit of formal training (Hunt \& Swartz, 2017; Searight \& Armock, 2013). A remarkable study in a multilingual city found that although $70 \%$ of therapists had worked with an interpreter, less 
than 3\% had received relevant training (Brisset et al., 2014). Without widespread training, a negative cycle persists: (a) Psychology students who receive no training on language accommodations may presume that English-only therapy is satisfactory and remain unaware of the needs of individuals with LEP; (b) those with LEP continue to perceive that mental health services are unavailable to them; and (c) lacking clients with LEP, clinical sites and training programs may see no urgent need to provide language accommodations. Systematic training would help future clinicians interrupt this cycle in order to meet the currently neglected mental health needs of potential clients with LEP.

Guidelines exist for working with interpreters in mental health settings (Miletic, Piu, Minas, Stankovska, Stolk, \& Klimidis, 2006; Paone \& Mallott, 2008; Searight \& Searight, 2009; Tribe \& Lane, 2009; Tribe \& Thompson, 2011). However, training and practice standards are not yet systematized in North America; thus instructors and clinicians are left to deal with linguistic barriers through their own understanding of available recommendations (Searight \& Armock, 2013). To provide clarity for intructors, trainees, and clinicians, we synthesized the literature to identify the foundational skills that therapists should acquire. We distilled nine discrete components of practice that instructors can address during professional training (Table 1).

\section{Addressing Language Interpretation in Multicultural Courses}

Already mandated in APA's accreditation standards (2015), training in multicultural considerations provides an obvious forum for addressing the proposed nine areas of instruction: "Knowledge and skills in working with interpreters should be included in graduate courses on multiculturalism" (Searight \& Searight, 2009, p. 449). However, given the breadth and complexity of multicultural psychology coursework (Boyer-Fier \& Ramsey, 2005), we sought to ascertain which of the nine areas of competence (Table 1) instructors consider most important so 
that the field could emphasize those skills sufficiently for training to become widespread.

Given the apparently inadequate training and attention to language accommodations and the many concerns among mental health professionals about language interpretation (Villalobos et al., 2016), we sought to assess the extent of relevant professional training as well as graduate instructors' concerns, perceived barriers, and recommendations regarding such training. We surveyed multicultural psychology course instructors, considering them as the faculty members most informed about the APA guidelines (1993, 2003) addressing linguistic diversity. We also considered them to be in the best position (a) to evaluate current training efforts specific to working with interpreters, (b) to recognize barriers to such training, (c) to offer potential solutions to the problems identified, and (d) to facilitate or provide relevant training in the future. Specifically, we addressed the following research questions:

1. What are instructors' current practices for training students on working with language interpretation in therapy?

2. Which of the nine proposed skill areas do instructors consider most important for working with language interpreters?

3. What barriers interfere with incorporating the content into multicultural courses?

4. What recommendations do the instructors provide to the field as a whole for meeting the needs of potential clients who communicate in languages other than English?

\section{Method}

\section{Participants and Procedures}

The investigators solicited responses from current instructors of multicultural psychology courses in APA-accredited counseling and clinical doctoral programs. Contact information for the instructors was provided by 192 of 241 doctoral programs; 49 programs (20\%) did not 
provide that contact information online and declined to provide it in response to our emailed and phone call requests. Identified instructors were sent an email requesting survey participation, along with an IRB-approved statement of informed consent and a \$10 incentive Amazon electronic gift card. A paper version of the survey and postage-paid return envelope were also mailed to each instructor. A follow-up email request to participate was sent one week after the postal letter. Of the 192 surveys distributed, 117 were verified as having been opened online, with 85 completed. An additional 17 completed surveys were returned via postal mail. Thus 102 participated (53\% response rate; $42 \%$ of APA-accredited programs represented).

Of the 102 instructors completing the survey, 60 were affiliated with clinical psychology and 38 with counseling psychology; four did not indicate affiliation. Respondents had taught the multicultural course for an average of 7.5 years, with an average of 18 students in each course. The course was taught once a year by $61 \%$ of participants, less than once a year by $33 \%$, and every semester by $6 \%$. Because we have conducted previous research on multicultural psychology, some instructors known to us may have had concerns that we would identify them as participants if given demographic information, so to increase participation rates we did not collect information on participant age, gender, and race (having no reason to believe that those variables would systematically influence the training provided).

\section{Survey Questions and Data Analyses}

The survey inquired about instructors' current educational practices and personal opinions related to language interpretation in psychotherapy. Participants were asked to rank the relative importance of nine areas of instruction for working with language interpreters (Table 1). We also requested feedback from course instructors regarding implementation of the nine skill areas, as well as potential barriers to their implementation. 
We followed procedures of conventional content analysis (Hsieh \& Shannon, 2005) to systematically classify open-ended responses into conceptually distinct categories: (a) reading responses repeatedly to obtain a sense of the whole, (b) deriving initial codes from the text, (c) recording the initial codes, (d) sorting codes based on relationships, (e) reducing conceptual overlaps, (f) writing definitions of the final codes, and (g) analyzing all responses using the coding scheme. The primary author and a research assistant independently reviewed participants' responses, worked together to establish coding frames, independently coded participants' responses, and verified inter-rater reliability during consensus meetings to reconcile discrepancies. An adequate inter-rater reliability of $83 \%$ was attained.

\section{Results}

\section{Language Interpretation Instruction in Multicultural Courses}

When asked to specify the percentage of their multicultural psychology course covering various topics, instructors' responses averaged $11 \%$ of the course addressing general language issues, with more coverage received by racial issues (46\%) and other topics such as gender (43\%). Some content relevant to language interpretretation in therapy was included in 55 (54\%) multicultural psychology courses, with 39 (38\%) not covering the topic and with $8(8 \%)$ instructors not reporting. Those who did teach the topic typically (40\%) spent an hour or less, with only 16 instructors ( $16 \%$ of the total sample) spending more than two hours on the topic.

In response to a request on the survey to rate the importance of training students to work with professional interpreters in psychotherapy, the average rating was $7.33(S D=1.9)$ on a scale from 0 (unimportant) to 10 (very important). An open-ended survey question asked instructors to specify how they trained students to work with language interpreters. Instructors typically covered language interepretation as one component of a broader conversation about language 
and communication. One instructor stated,

The implications of language differences are discussed . . . includ[ing] worldview. The importance of and how to interface with cultural resources (e.g., local healers, holders of cultural wisdom) are part of this. [We] discuss interpreter [selection], confidentiality issues, and pre-session work (e.g., letting interpreter know the issues [and] key terms). Instructors covered the topic of language interepretation in lectures/discussions $(n=34$; $40 \%)$ or referred students to relevant resources and readings $(n=25 ; 29 \%)$. Nine instructors $(10 \%)$ invited guest lecturers skilled in interpretation, nine (10\%) involved students in practicing relevant skills through role playing and similar methods, and five $(6 \%)$ mentioned training during practicum or clinical supervision. A few provided detailed information about the topic and implemented multiple strategies that seemed to be working well. One indicated,

I start with exercises where students act as [interpreters]... We then discuss some barriers students can foresee in working with interpreters. We then develop guidelines [for] working with interpreters (e.g., selecting appropriate interpreters, clarifying roles). [Afterward] students complete readings on working with interpreters.

Another volunteered,

I use slides from a webinar that discuss interpreter roles (conduit, clarifier, cultural broker, etc.), why professional interpreters should be used (versus a family member or other ad-hoc interpreter), [how to conduct] the pre-session meeting. . negotiate the introduction (confidentiality, etc.), and speak in brief segments and directly to the patient.

\section{Rankings of and Intentions to Teach the Proposed Nine Skill Areas}

The survey listed nine areas of competence for working with language interpreters (Table 1), which instructors ranked in terms of their value for trainees. As shown in Table 2, instructors 
tended to rank discussing interpreters' roles, responsibilities, and confidentiality as the most important, followed by facilitating effective communication in the triad, ethically selecting an interpreter, and orienting interpreters prior to the session. The topic consistently ranked least important was conducting a post-session debriefing with the interpreter.

After instructors ranked the nine skill areas, they were asked to rate the percentage of likelihood $(0-100 \%)$ that they would teach those skills in their multicultural psychology course. Responses averaged $64 \%$ (median of 70\%), ranging from 0 to 100, with substantial variability $(S D=32)$, indicating overall positive but clearly mixed intentions. To better understand the variability in instructors' intentions, we analyzed their perceived barriers to content integration.

\section{Barriers to Covering Relevant Skills in Multicultural Courses}

Instructors of multicultural pschology courses were asked to describe barriers to teaching skills for working with language interpreters. Table 3 summarizes the content of open-ended responses from 81 participants. The instructors consistently mentioned time limitations, such as, "There are so many topics that could be covered. Not every topic can be covered in a deep and meaningful way within a 45-hour course." Some described limited resources for training, for instance, "We do not have much access to professional interpreters, so we often don't have the choice even when it would be very helpful."

Some instructors acknowledged that their own "inexperience with working with an interpreter in psychotherapy" made them reluctant to address the topic with students. One admitted, "Many instructors are not competent themselves. I came to competence accidentally, having worked as an interpreter/translator for several years before applying for graduate school."

Concerns mentioned less frequently included students' resistance to multiculturalism and the prevailing norm that therapy should be conducted in the language of the therapist, rather than 
accommodate language needs of potential clients. One instructor observed, "The large majority of my students are monolingual English speakers, and I think there can be a lack of appreciation or understanding regarding [how one's] 'native tongue' influences one's expression of self, emotionality, etc." Another added "Ethnocentrism — not wanting to do the extra work involved in using interpreters." Thus barriers were not limited to the institutional or systemic level.

\section{Instructors' Recommendations for Addressing Language Interpretation}

Recognizing that multicultural course instructors work to promote multicultural competence among other psychologists (Smith \& Trimble, 2016), we asked them to provide specific recommendations that go beyond APA's (1993) longstanding position that psychologists should interact in the language requested by the client when possible. Accordingly, 50 instructors provided a total of 65 conceptually distinct responses, summarized at the bottom of Table 3 .

Several respondents expressed a desire for APA to assert guidelines that clients receive services in their preferred language. Other suggestions included providing additional resources and incentives for training programs to address language issues: "Adding this as a competency for APA-accredited programs is a good start. However, careful attention should be paid to what resources will be available to programs to support the use of interpretation services." Other instructors recommended recruiting students who can communicate in languages other than English or providing online professional training. Some instructors felt that training programs could be held accountable for enabling students to work with LEP clients: "Language skills are not valued in tangible and substantive ways during APA accreditation processes. Create resources and incentives for training programs to train students with a variety of language skills." Overall, instructors mentioned the need for training. For instance, an instructor who at that time provided no training on the topic wrote that the need for such training "has become increasingly 
apparent for our students at certain clinical practicum sites."

\section{Discussion}

Psychologists seek to provide mental health services to all individuals in need of those services, including clients with limited English proficiency (APA, 2003). Mental health clients strongly prefer to communicate in their primary language and have better clinical outcomes when they do (Espín, 2013; Soto et al., 2018). When the optimal arrangement of multilingual therapist (Villalobos et al., 2016) is unavailable, accommodations should be made for language interpretation by trained professionals (APA, 1993; Brach \& Fraserirector, 2000).

Considering multiple ethical issues and problems inherent in language interpretation, the professional literature emphasizes the need for training in working with interpreters (Searight \& Armock, 2013; Yakushko, 2010). We found that such training was generally inadequate. In our survey of multicultural psychology instructors in APA-accredited programs 55 of 102 (54\%) reported at least some relevant training. Very few instructors $(n=16 ; 16 \%)$ provided in-depth training. These findings suggest a need for improvement. Despite barriers such as time constraints, overloaded curiculum and limited resources, instructors generally expressed willingness to provide additional training on this topic in future coursework.

\section{Implications for Professional Training in Psychology}

Professional psychology programs can better prepare students to meet the needs of individuals who are Deaf as well as needs of immigrants, refugees, and asylum seekers with LEP (e.g., Glickman, 2013; Prendes-Lintel, 2001). Optimally programs will seek out multilingual trainees and provide them with needed skills (Brach \& Fraserirector, 2000; Villalobos et al., 2016). However, given the diversity of languages spoken by potential clients, programs would do well to designate a place in the curriculum where therapists learn skills necessary for working 
with language interpreters (Yakushko, 2010), providing instructors with the needed support.

Content placement. Skills necessary for working with language interpreters can be covered in practicum or in a multicultural psychology course (Searight \& Searight, 2009). However, instructors of these courses deal with a large number of highly complex topics (BoyerFier \& Ramsey, 2005)—-having too much material and insufficient time. Surveyed instructors of multicultural psychology courses believed language interpretation to be an important but nonessential topic. Although some instructors could re-prioritize topics, others might find detailed coverage unfeasible, necessitating program directors to require that students complete a separate workshop or online training module (Searight \& Armock, 2013; Yakushko, 2010).

Resource accommodations. Several instructors of multicultural courses acknowledged that their own lack of training in working with language interpreters restricted them from providing students with relevant skills. Graduate programs could provide resources to support professional development via webinars or workshops. Programs could also identify professionals trained in mental health interpretation who are willing to provide ongoing consultation and recommend available resources. Programs could also disseminate to students and faculty the contact information for local interpreters (listed by language). In rural areas where local resources are insufficient, programs can provide links to several online interpretation services.

Curriculum additions. Many multicultural course instructors indicated their intention to add training on working with language interpreters to their curriculum. In addition to obtaining relevant information for lectures/discussions and assigned readings, instructors can seek out experienced professionals as guest presenters to share specific skills and case examples. Further information valuable to students is available on many websites such as those maintained by the U.S. Office of Civil Rights (www.hhs.gov/ocr/lep/) and the LEP Federal Interagency website 
(www.lep.gov/resources/resources.html), and online training modules have been developed (e.g., Ikram, Essink-Bot, \& Suurmond, 2015). Instructors can provide students opportunities to practice the skills they learn: for example in role plays and in practicum settings. Training for multicultural competence necessitates skill acquisition (Sue et al., 1992).

Optimal training will be grounded in competency-based education (Hatcher et al., 2013). The nine areas of competence for working with language interpreters in psychotherapy summarized in Table 1 provide a structure to course instructors and others. Survey respondents considered the most essential components to be ethical selection of an interpreter; effective communication in the triad; and management of roles, responsibilities, and confidentiality. Instructors can emphasize those particular topics while also mentioning the others.

Systematic support. Finally, survey respondents suggested that increased systematic attention would be given to client language accommodations if training programs (a) understood associated APA guidelines (1993, 2003) and ethical considerations, (b) received additional organizational support, and (c) reported during accreditation reviews. Participants also endorsed the need to attract and train students fluent in languages other than English, promote access to online training, and conduct additional research.

\section{Implications for Future Research}

Scholarship in other professions supports language interpreters (e.g., Jacobs \& Diamond, 2017), but limited research has been conducted in mental health settings (Paone \& Malott, 2008). The need for successful cross-language mental health therapy only continues to grow. Yet while demand increases, little empirical information exists about what is or is not successful when engaging in this work. The danger of this gap in knowledge is that at best there are unknown factors contributing to successful treatment outcomes, and at 
worst clients are experiencing harm because of impairment in the clinician-interpreter working relationship. (Becher \& Wieling, 2015, p. 456)

Potential for difficulties. Although language accommodations improve client outcome (Soto et al., 2018) and language interpretation does not necessarily diminish the therapeutic alliance (Villalobos et al., 2016), language interpretation involves many errors, some costly and damaging to clients (Miletic et al., 2006; Searight \& Armock, 2013). Instructors need to openly address common problems in mental health settings (e.g., confidentiality, interpreter accuracy, ad hoc interpretation; Flores, 2005; Jacobs \& Diamond, 2017, Miletic et al., 2006). Different languages express underlying cultural conceptualizations; thus future research should also attend to cultural worldview alignment (Brisset et al., 2013; Tribe \& Raval, 2003; Yakushko, 2010).

Question of need. A general lack of awareness of people with LEP persists (e.g., Ohtani et al., 2015). In response to our survey, some instructors indicated that specialized training to work with language interpreters may be unnecessary in rural areas with limited language diversity or for students who have no interest in working with LEP individuals. Future scholarship can address the needs and challenges of rural areas, but we can acknowledge that there are no locations without Deaf individuals. Our profession can do more to combat audism and associated assumptions regarding universal spoken English (Eckert \& Rowley, 2013). Training can help correct the false belief that few people have LEP, just because trainees may not have interacted with them, and emphasize that psychologists remain responsibile for their treatment (APA, 1993, 2003), even in rural areas (e.g., via professional internet interpretation).

Pragmatic issues. Instructors will need to address such issues as interpreter availability, effectiveness, and cost. For instance, technology and inter-agency cooperation can increase the availability and decrease the costs of language interpretation (Masland, Lou, \& Snowden, 2010), 
potentially increasing revenue by expanding clients' access to services, decreasing misdiagnoses and related costly errors, and increasing clients' outcomes and satisfaction (Brisset et al., 2014).

\section{Study Limitations}

Several limitations characterized this study. First, $20 \%$ of APA-accredited doctoral programs did not respond to our request to identity the multicultural course instructor. If programs failing to provide contact information systematically differed from other programs (e.g., using temporary/adjunct instructors, integrating multicultural content across many courses), then our data may misrepresent actual practices despite the $53 \%$ rate of returned surveys.

A second limitation concerned the qualitative data, consisting of participant responses to written prompts on the survey. Many participants wrote responses, but they were usually briefthus providing limited coverage of a complex topic. We could have obtained richer qualitative data had we conducted follow-up in-depth interviews with a subsample of the respondents. For instance, we might have learned more from the perspectives of five of 102 respondents who opposed working with interpreters in psychotherapy, preferring to recruit and train bi-lingual students or to require the study of a second language during graduate training.

A third possible limitation concerns the target sample. In designing the study we felt confident that if programs provided any instruction regarding how to work with language interpreters, the instructors of multicultural courses would be the most likely to know about it. Survey results indicated that some coverage of the topic may be occurring in practicum and other courses, but our survey did not specifically evaluate those settings. Future research could investigate ways to provide relevant instruction in practicum and through online modules.

\section{Conclusion}

Multicultural training often focuses on issues of race and culture (e.g., Smith \& Trimble, 
2016), but those considerations overlap with language (Brach \& Fraserirector, 2000; Espín, 2013). The experiences and disadvantages of over 26 million people in the U.S. who have LEP (U.S. Census, 2016) require attention beyond current practices in psychology training programs. In our national survey, instructors of multicultural psychology courses endorsed the importance of training therapists to work with language interpreters. Although instructors identified several barriers to training students, they expressed general willingness to increase and improve that training. To support that work, we summarized nine relevant areas of competence. If current patterns continue and programs provide little to no training on the issue, then trainees will encounter cross-cultural communication challenges for which they are unprepared. Although at present it may be normative to provide psychotherapy exclusively in English, the negative consequences (e.g., Flores, 2005) continue to affect immigrants, refugees, and asylum seekers whose status in the U.S. is already precarious under intense federal scrutiny.

Over a decade ago in the American Psychologist, Snowden and colleagues (2007) called attention to the federal mandate (Title VI of the Civil Rights Act) for public services to offer language acommodations and also to continued barriers faced by individuals with LEP in mental health settings. Since that time psychologists have made limited efforts at language accommodations (Durbin et al., 2017; Searight \& Armock, 2013), yet medical clinics and hospitals have increasingly provided language accommodations (e.g., Chiam et al., 2017; Hsieh, 2016; Masland et al., 2010). Many medical schools train students to work with interpreters (e.g., Ikram et al., 2015), and over 66\% offer training in languages such as Spanish (Morales et al., 2015). It seems appropriate for psychologists to do the same, implementing our own professional guidelines (APA, 1993, 2003; Fouad et al., 2017) by training psychologists to address the needs of individuals and families unable to communicate mental health concerns in English. 


\section{References}

American Psychological Association. (1993). Guidelines for providers of psychological services to ethnic, linguistic, \& culturally diverse populations. American Psychologist, 48, 45-48.

American Psychological Association. (2003). Guidelines on multicultural education, training, research, practice, and organizational change for psychologists. Retrieved from http://www.apa.org/pi/oema/resources/policy/multicultural-guideline.pdf

American Psychological Association. (2015). Standards of accreditation for psychology. http://www.apa.org/ed/accreditation/about/policies/standards-of-accreditation.pdf

American Psychological Association. (2018). Find a therapist. Retrieved from locator.apa.org

Becher, E. H., \& Wieling, E. (2015). The intersections of culture and power in clinician and interpreter relationships: A qualitative study. Cultural Diversity and Ethnic Minority Psychology, 21(3), 450. https://doi.org/10.1037/a0037535

Boyer-Fier, E., \& Ramsey, M. L. (2005). Ethical challenges in the teaching of multicultural course work. Multicultural Counseling and Development, 33, 94-107.

Brach, C., \& Fraserirector, I. (2000). Can cultural competency reduce racial and ethnic health disparities? A review and conceptual model. Medical Care Research and Review, 57, 181-217. https://doi.org/10.1177/1077558700057001S09

Brisset, C., Leanza, Y., \& Laforest, K. (2013). Working with interpreters in health care: A systematic review and meta-ethnography of qualitative studies. Patient Education and Counseling, 91(2), 131-140. https://doi.org/10.1016/j.pec.2012.11.008

Brisset, C., Leanza, Y, Rosenberg, E., Vissandjée, B., Kirmayer, L., Muckle, G., Xenocostas, S., \& Laforce, H. (2014). Language barriers in mental health care: A survey of primary care practitioners. Journal of Immigrant and Minority Health, 16(6), 1238-1246.

Chiam, T. C., Hoover, S., Mosby, D., Caplan, R., Dolman, S., Gbadebo, A., Mayer, F., ... \& Jackson, E. (2017). Meeting demand: A multi-method approach to optimizing hospital 
language interpreter staffing. Journal of Hospital Administration, 6(2), 21-29.

Derr, A. S. (2015). Mental health service use among immigrants in the United States: A systematic review. Psychiatric Services, 67(3), 265-274.

Durbin, A., Sirotich, F., \& Durbin, J. (2017). English language abilities and unmet needs in community mental health services: A cross-sectional study. The Journal of Behavioral Health Services \& Research, 44(3), 483-497. https://doi.org/10.1007/s11414-016-9503-1

Eckert, R. C., \& Rowley, A. J. (2013). Audism: A theory and practice of audiocentric privilege. Humanity \& Society, 37(2), 101-130. https://doi.org/10.1177/0160597613481731

Espín, O. M. (2013). Making love in English: Language in psychotherapy with immigrant women. Women \& Therapy, 36, 198-218.https://doi.org/10.1080/02703149.2013.797847

Flores, G. (2005). The impact of medical interpreter services on the quality of health care: A systematic review. Medical Care Research and Review, 62(3), 255-299.

Fouad, N. A., Santana, M., \& Ghosh, A. (2017). Empirical influence of the multicultural guidelines: A brief report. Cultural Diversity \& Ethnic Minority Psychology, 23, 583-87.

Glickman, N. S. (2013). Culturally affirmative psychotherapy with deaf persons. NY:Routledge.

Hatcher, R. L., Fouad, N. A., Campbell, L. F., McCutcheon, S. R., Grus, C. L., \& Leahy, K. L. (2013). Competency-based education for professional psychology: Moving from concept to practice. Training and Education in Professional Psychology, 7(4), 225-234.

Hsieh, E. (2016). Bilingual health communication. New York, NY: Routledge.

Hsieh, H., \& Shannon, S. E. (2005). Three approaches to qualitative content analysis. Qualitative Health Research, 15, 1277-1288. https://doi.org/10.1177/1049732305276687

Hunt, X., \& Swartz, L. (2017). Psychotherapy with a language interpreter: Considerations and cautions for practice. South African Journal of Psychology, 47(1), 97-109.

Ikram, U. Z., Essink-Bot, M. L., \& Suurmond, J. (2015). How we developed an effective e- 
learning module for medical students on using professional interpreters. Medical Teacher, 37(5), 422-427. https://doi.org/10.3109/0142159X.2014.939579

Jacobs, E. A., \& Diamond, L. C. (Eds.). (2017). Providing health care in the context of language barriers: International perspectives. Bristol, UK: Multilingual Matters.

Masland, M. C., Lou, C., \& Snowden, L. (2010). Use of communication technologies to costeffectively increase the availability of interpretation services in healthcare settings. Telemedicine and e-Health, 16(6), 739-745. https://doi.org/10.1089/tmj.2009.0186

Mikkelson, H. (2016). Introduction to court interpreting. New York, NY: Routledge.

Miletic, T. P., Piu, M., Minas, H., Stankovska, M., Stolk, Y., \& Klimidis, S. (2006). Guidelines for working effectively with interpreters in mental health settings. Melbourne, Australia: Victorian Transcultural Psychiatry Unit.

Morales, R., Rodriguez, L., Singh, A., Stratta, E., Mendoza, L., Valerio, M., \& Vela, M. (2015). National survey of medical Spanish curriculum in US medical schools. Journal of General Internal Medicine, 30, 1434-1439. https://doi.org/10.1007/s11606-015-3309-3

Ohtani, A., Suzuki, T., Takeuchi, H., \& Uchida, H. (2015). Language barriers and access to psychiatric care: A systematic review. Psychiatric Services, 66, 798-805.

Paone, T. R., \& Malott, K. M. (2008). Using interpreters in mental health counseling: A literature review and recommendations. Journal of Multicultural Counseling and Development, 36(3), 130-142. doi:10.1002/j.2161-1912.2008.tb00077.x

Prendes-Lintel, M. (2001). A working model in counseling recent refugees. In J. G.Ponterotto, J. M. Casas, L. A. Suzuki, \& C. M. Alexander (Eds.), Handbook of multicultural counseling (pp. 729-752). Thousand Oaks, CA: Sage.

Searight, H. R., \& Armock, J. (2013). Foreign language interpreters in mental health practice: A literature review \& research agenda. North American Journal of Psychology, 15, 17-38. 
Searight, H. R., \& Searight, B. K. (2009). Working with foreign language interpreters: Recommendations for psychological practice. Professional Psychology: Research and Practice, 40(5), 444-451. https://doi.org/10.1037/a0016788

Smith, T. B., \& Trimble, J. E. (2016). Foundations of multicultural psychology: Research to inform effective practice. Washington, DC: American Psychological Association.

Soto, A., Smith, T. B., Griner, D., Domenech Rodríguez, M., \& Bernal, G. (2018). Cultural adaptations and therapist multicultural competence: Two meta-analytic reviews. Journal of Clinical Psychology.

Snowden, L. R., Masland, M., \& Guerrero, R. (2007). Federal civil rights policy and mental health treatment access for persons with limited English proficiency. American Psychologist, 62, 109-117. https://doi.org/10.1037/0003-066X.62.2.109

Sue, D. W., Arredondo, P., \& McDavis, R. (1992). Multicultural counseling competencies and standards: A call to the profession. Journal of Counseling \& Development, 70, 477-486.

Tribe, R., \& Lane, P. (2009). Working with interpreters across language and culture in mental health. Journal of Mental Health, 18(3), 233-241. doi:10.1080/09638230701879102

Tribe, R., \& Raval, H. (2003). Working with interpreters in mental health. NY: Routledge.

Tribe, R., \& Thompson, K. (2011). Developing guidelines on working with interpreters in mental health: Opening up an international dialogue? International Journal of Culture and Mental Health, 4(2), 81-90. https://doi.org/10.1080/17542863.2010.503365

United States Census Bureau. (2016). American community survey 2016 data release. Retrieved from https://www.census.gov/programs-surveys/acs.

Yakushko, O. (2010). Clinical work with limited English proficiency clients: A phenomenological exploration. Professional Psychology: Research and Practice, 41, $449-455$. 
Table 1

Areas of Competence for Working with Language Interpreters in Mental Health Therapy

\section{Ethically select an interpreter}

Ascertain client language needs and dialect. Evaluate interpreters' experience with mental health interpreting, certification, cultural/linguistic background (compatibility with client dialect, ethnicity, gender, age, religion, etc.), interpersonal skills, stigma, availability for ongoing therapy.

\section{Orient the interpreter prior to the session}

Discuss confidentiality and boundaries. Agree on interpreter role (e.g., cultural broker, advocate). Clarify mental health terminology and treatment processes. Confirm contractual arrangements.

\section{Set up the session to enable interpretation}

Arrange logistics, including translated written materials, simultaneous or sequential interpretation, first or second person pronoun interpretation, seating for proximate settings and technology for remote settings. Account for time, twice as long as normal. Adapt institutional procedures as needed.

\section{Discuss roles, responsibilities, and confidentiality in the triad}

Prior to the session orient client to procedures. In session discuss roles of the clinician, interpreter, and client. Address confidentiality, therapy processes, and client concerns. If the interpreter is not certified, provide procedural safeguards. Specify common issues to avoid in interpreted sessions.

\section{Facilitate effective communication in the triad}

Communicate in the triad using succinct verbalizations, without technical/slang terms. Avoid side conversations and compound questions. Maintain eye contact with client. Provide and elicit descriptions. Emphasize accuracy; avoid using shortcuts to hurry the session. Confirm client perception and understanding, noting varied instances. Review and confirm key points at session end.

\section{Exchange relevant cultural and linguistic information}

Gather cultural information from the interpreter to understand the client's beliefs/stigma, inform the diagnosis, and/or modify the treatment plan. Verify cultural equivalence of concepts or find more compatible terms/metaphors. Guard against oversimplification of complex cultural concepts.

\section{Address relationship dynamics in the triad}

Address issues such as anxiety, power dynamics, minimization of symptoms, inappropriate interpreter interventions, transference/countertransference that impact working alliance in the triad.

\section{Conduct a post-session debriefing with the interpreter}

Discuss impressions of the session and evaluate accuracy of interpretation, client comprehension, and active involvement. Settle contractual, financial, and other arrangements with the interpreter. Plan for future sessions; maintain interpreter continuity with the same client.

\section{Assess interpreter comfort, fit, and needs}

Strengthen the working alliance with the interpreter. Assess the interpreter's comfort with the content during the session (including reactions to client trauma) and, if needed, provide emotional support, refer interpreter for further care, or suggest using a different interpreter. 
Table 2

Ranking of Nine Areas of Competence for Working with Language Interpreters in

Mental Health Services.

\begin{tabular}{llrrr}
\hline Rank & \multicolumn{1}{c}{ Competency } & Mean & Median & $S D$ \\
\hline & & & & \\
1 & Discuss roles, responsibilities, and confidentiality in the triad & 3.13 & 3.0 & 1.67 \\
2 & Facilitate effective communication in the triad & 3.61 & 3.0 & 2.20 \\
3 & Ethically select an interpreter & 4.08 & 4.0 & 1.86 \\
4 & Orient the interpreter prior to the session & 4.61 & 4.0 & 2.14 \\
5 & Exchange relevant cultural and linguistic information & 5.24 & 5.0 & 2.15 \\
6 & Address relationship dynamics in the triad & 5.65 & 5.0 & 2.09 \\
7 & Set up the session to enable interpretation & 5.83 & 6.0 & 2.20 \\
8 & Assess interpreter comfort, fit, and needs & 5.86 & 7.0 & 1.98 \\
9 & Conduct a post-session debriefing with the interpreter & 8.09 & 8.0 & 1.24 \\
\hline
\end{tabular}

Note. $n=98$. Four instructors did not rank the competencies from the list presented. 
Table 3

Reported Barriers to and Recommendations for Training to Work with Language Interpreters

\begin{tabular}{|c|c|c|c|}
\hline Topic & Example & $N$ & $\%$ \\
\hline \multicolumn{4}{|c|}{ Barriers (81 participants provided 109 conceptually distinct responses) } \\
\hline Time limitations/volume of topics & "Lack of time/space in the multicultural class" & 44 & 40 \\
\hline Limited resources for training & "Resources - access to people who speak other languages for role plays" & 19 & 17 \\
\hline Limited instructor experience/training & "Many instructors are not competent themselves" & 12 & 11 \\
\hline Ethnocentrism; limited motivation & "It can be hard to convince some less culturally aware students"; "Ethnocentrism" & 11 & 10 \\
\hline Access to professional interpreters & "Cost of interpreters and facility ability to pay for them" & 8 & 7 \\
\hline Intention/structure of course & "The class is multidisciplinary, so it is challenging to cover specific [disciplines]" & 8 & 7 \\
\hline Opposed to using interpreters & "Not valuing the use of interpreters" & 5 & 5 \\
\hline Relevance to future work & "Many students have not, or may not in the future, work with interpreters" & 2 & 2 \\
\hline \multicolumn{4}{|c|}{ Recommendations (50 participants provided 65 conceptually distinct responses) } \\
\hline Promote resources/guidelines/ethics & "APA can do a better job of disseminating these guidelines to training directors" & 23 & 35 \\
\hline Increase multilingual students & "Recruit more multilingual therapists"; "learn a language other than English" & 13 & 20 \\
\hline Non-classroom-based training/research & "Webinar trainings"; "Continue to research and present at conferences" & 13 & 20 \\
\hline Inclusion in accreditation review & "APA needs to enforce the guidelines during accreditation" & 8 & 12 \\
\hline Increase access to interpreters & "More access to interpreters; ways to pay for services"; "input from NLPA" & 5 & 8 \\
\hline Require certification/training & "Greater efforts to promote training and certification" & 3 & 5 \\
\hline
\end{tabular}

